\title{
Interest Rate Risk Measurement in Brazilian Sovereign Markets
}

Caio Ibsen Rodrigues de Almeida

Antonio Marcos Duarte Júnior

Cristiano Augusto Coelho Fernandes

\author{
Professor Adjunto, Ibmec Business School, \\ Rio de Janeiro \\ Professor, Ibmec Business School, Rio de Janeiro \\ Professor Assistente, Pontifícia Universidade \\ Católica do Rio de Janeiro
}

\section{RESUMO}

Os mercados emergentes de renda fixa são alternativas interessantes para investimentos. Devido ao elevado nível de incerteza existente em tais mercados, a mensuração dos riscos de mercado de uma carteira de investimentos é fundamental para que se evite um nível elevado de perdas. Uma das medidas de risco de mercado mais utilizadas é o Value at Risk, baseado na distribuição de probabilidades de perdas-ganhos da carteira sob análise. A estimação desta distribuição requer, no entanto, a estimação prévia da distribuição de probabilidades das variações da estrutura a termo da taxa de juros. Uma possibilidade interessante para a estimação de tal distribuição é efetuar uma decomposição da função de spread da estrutura a termo em uma combinação linear de Polinômios de Legendre. Exemplos numéricos do mercado internacional de títulos soberanos brasileiros são apresentados para ilustrar o uso prático desta nova metodologia.

\section{PALAVRAS-CHAVE}

mercados emergentes, taxas de juros, gerenciamento de riscos

ABSTRACT

Fixed income emerging markets are an interesting investment alternative. Measuring market risks is mandatory in order to avoid unexpected huge losses. The most used market risk measure is the Value at Risk, based on the profit-loss probability distribution of the portfolio under consideration. Estimating this probability distribution requires the prior estimation of the probability distribution of term structures of interest rates. An interesting possibility is to estimate term structures using a decomposition of the spread function into a linear combination of Legendre polynomials. Numerical examples from the Brazilian sovereign fixed income international market illustrate the practical use of the methodology.

KEY WORDS

emerging markets, interest rate, risk management

JEL Classification

C5I, C52, F2I, GI5 


\section{INTRODUCTION}

Fixed income emerging markets developed quickly during the last decade. Higher international liquidity, the interest of portfolio managers in diversifying internationally, and the continuous improvement of risk control by international rating agencies are three reasons for such a development.

Some of the most liquid instruments traded in fixed income emerging markets are the so-called Brady bonds. (FABOZZI \& FRANCO, 1997). They are dollar denominated sovereign instruments, originated from the restructuring of defaulted bank loans of countries located in Latin America, Central and Eastern Europe, Middle East, Africa and Asia.

Pricing and hedging these instruments is not easy due to their usually complex cash flows. They may present floating (for instance, depending on the LIBOR rates) or step up interest payments, amortize or capitalize principal before maturity, contain embedded options, as well as offer collateralized principal and/or interest payments.

Other fixed income instruments in the emerging debt market include bank loans, local issues, and eurobonds. Eurobonds are bonds issued in a foreign currency, in a foreign country. Interest on them has been growing steadily due to the improving credit rating of certain emerging markets, with special attention directed, more recently, to Global bonds, which are eurobonds issued simultaneously in several countries.

Whenever investing in emerging markets one must pay special attention to risk management. Controlling risk is mandatory in order to avoid unexpected high losses. The Value at Risk (VaR; JORION, 2001) of a portfolio, obtained as a percentile of the profit-loss probability distribution of the portfolio, is one of the most frequently adopted market risk measures. On its turn, in fixed income markets, the profit-loss probability distribution of the portfolio is closely related to the term structure of interest rates probability distribution. In other words, if we are interested in calculating the $\mathrm{VaR}$ of fixed income portfolios, we need first to estimate the probability distribution of the variations of the term structure of interest rates. 
Vasicek and Fong (1982) suggest estimating the U.S term structure of interest rates applying a regression model based on exponential splines. Litterman and Scheinkman (1991) verifies, using Principal Component Analysis (PCA; MARDIA et al., 1992), that more than $90 \%$ of the U.S term structure of interest rates movements were explained by just three orthogonal factors. Several applications were proposed in the finance literature following that. For instance, Singh (1997) uses PCA to estimate the market risk of fixed income instruments in the US market. Barber and Copper (1996) propose an immunization strategy also based in PCA to generate optimal hedges.

Almeida et al. (1998) suggests a modeling approach for term structures of interest rates in emerging markets. The model is based on a decomposition of the term structure in a risk free benchmark curve plus a spread function representing the sovereign credit risk spread. This spread function, on its turn, is decomposed into a linear combination of Legendre polynomials. (LEBEDEV, 1972). An extension to this model, which considers the relative credit risk among the assets included in the estimation process, is possible. (ALMEIDA et al., 2000). In this extension, the relative credit risk is captured by considering the rating of each asset in the evaluation of the credit spread function. This enhanced methodology provides more accurate estimates of term structures, at the expense of more computational complexity. Since our interest in this article is to consider market risk measurement, instead of credit risk measurement, it is not crucial to adopt the approach suggested in Almeida et. al. (2000). If the reader is considering estimating the credit risk exposure of portfolios (alone or together with the market risk exposure), adopting the approach suggested in Almeida et. al. (2000) becomes necessary.

In this article, a methodology for estimating the $\mathrm{VaR}$ of portfolios in fixed income emerging markets is proposed. We estimate the historical probability distribution for the variations of the benchmark curve, as well as for each orthogonal factor responsible for movements of the spread function, obtaining the historical probability distribution of variations for the whole term structure. Two numerical examples using data from the Brazilian sovereign 
fixed income market are presented. These examples illustrate the VaR estimation of a portfolio composed by Brazilian Brady and Global bonds.

The article is organized as follows. Section 1 presents the model for the estimation of term structures of interest rates in emerging markets, and the methodology used in our examples. Section 2 presents the numerical examples. Last section concludes the article.

1. TERM STRUCTURE OF INTEREST RATES IN EMERGING MARKETS

\subsection{Definition}

The term structure of interest rates in a fixed income emerging market can be modeled as:

$$
R(t)=B(t)+\sum_{n \geq 0} c_{n} P_{n}\left(\frac{2 t}{\lambda}-1\right), \forall t \in[0, \lambda]
$$

where $t$ denotes time, $B(t)$ is a benchmark curve (for instance, the U.S. term structure of interest rates), $P_{n}$ is the Legendre polynomial of degree $n$ (LEBEDEV, 1972), $c_{n}$ is a parameter, and $\lambda$ is the longest maturity of a bond in the emerging market under consideration.

The price of a bond $(p)$ relates to the term structure by:

$$
p=\sum_{i=1}^{n_{A}} C_{i} \exp \left(-t_{i} R\left(t_{i}\right)\right)
$$

where $C_{t}$ denotes the cash flow paid by the bond on time $t_{i}$, and $n_{A}$ denotes the total number of cash flows paid by the bond.

The Legendre polynomial of degree $n$ is defined (in the compact set $[-1,1]$ ) according to the following expression:

$$
P_{n}(x)=\frac{1}{2^{n} n !} \frac{d^{n}}{d x^{n}}\left(\left(x^{2}-1\right)^{n}\right), \forall n=0,1,2 \ldots .
$$

The first four Legendre polynomials are: 


$$
\begin{aligned}
& P_{0}(x)=1 \\
& P_{1}(x)=x \\
& P_{2}(x)=\frac{1}{2}\left(3 x^{2}-1\right) \\
& P_{3}(x)=\frac{1}{2}\left(5 x^{3}-3 x\right) .
\end{aligned}
$$

Their graphs are depicted in Figure 1. The first Legendre polynomial will be related to parallel shifts in the term structure, the second Legendre polynomial will be related to changes in slope of the term structure, the third Legendre polynomial will be related to changes in curvature of the term structure, and the fourth Legendre polynomial will be related to double changes in curvature of the term structure.

FIGURE I - FOUR LEGENDRE POLYNOMIALS

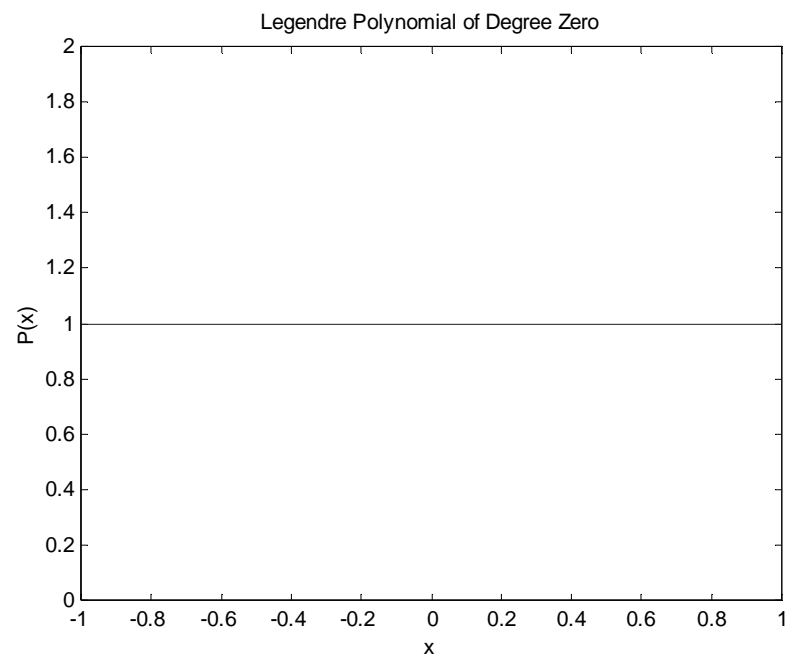



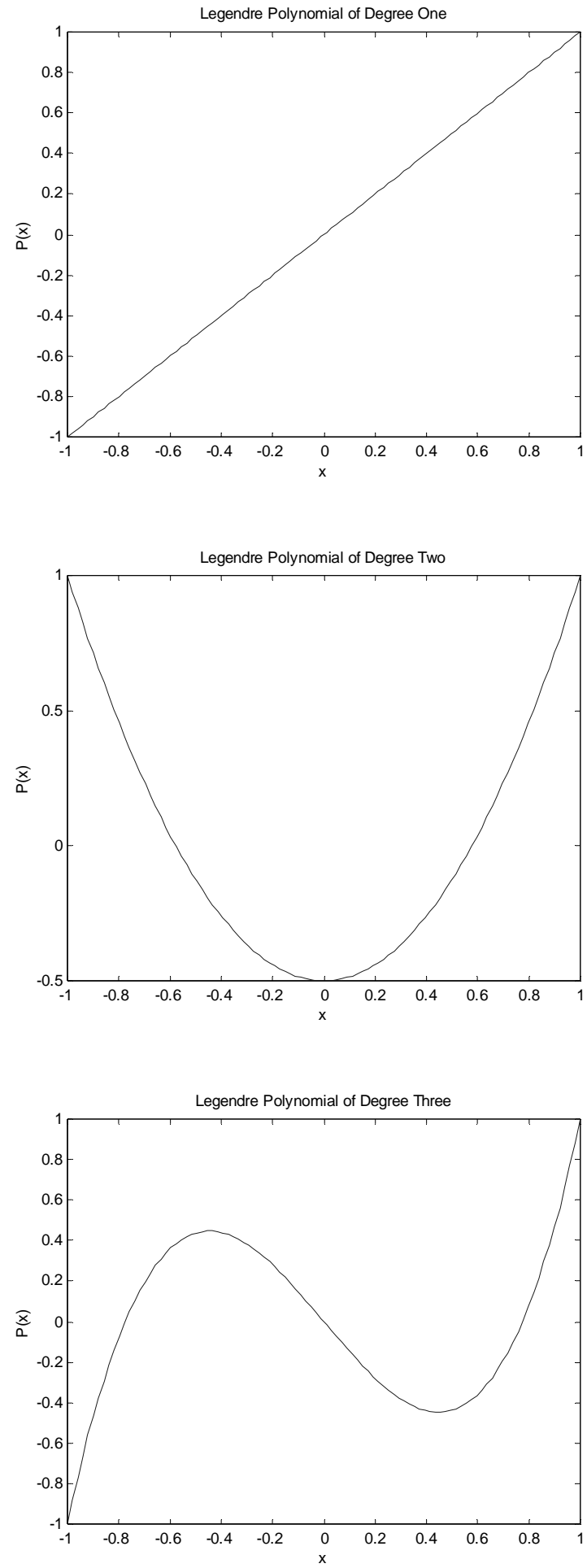

Est. econ., São Paulo, 34(2): 321-344, abr-jun 2004 


\subsection{Estimation}

The first step required is to estimate the coefficients $c_{0}, c_{1}, c_{2}, \ldots$, in Equation .

We define the discount function as:

$$
D(t)=e^{-R(t) t}, \forall t \in[0, \lambda]
$$

We assume that $m$ bonds are available in a particular instant of time for the estimation process. The estimation of the coefficients $c_{0}, c_{1}, c_{2}, \ldots$, is accomplished by the use of a non-linear regression equation given by:

$$
p_{j}+a_{j}+1_{j}^{p u t} o^{p}-1_{j}^{\text {call }} o^{c}=\sum_{l=1}^{J_{j}} u_{j l} D\left(t_{j l}\right)+e_{j}, \forall j=1,2, \ldots, m
$$

where $p_{j}$ denotes the price of the $j^{\text {th }}$ bond, $a_{j}$ denotes the accrued interest of the $j^{\text {th }}$ bond, $1_{j}^{\text {put }}$ and $1_{j}^{\text {call }}$ are dummy variables indicating the existence of embedded put and call options in the bond, $o^{p}$ and $o^{c}$ are unknown parameters related to the prices of the embedded put and call options, $f_{j}$ denotes the number of remaining cash flows of the $j^{t h}$ bond, and $t_{j l}$ the time remaining for payment of the $l^{\text {th }}$ cash flow $u_{i l}$ of the $j^{\text {th }}$ bond; $e_{j}$ is the random disturbance, with $E\left(e_{j}\right)=0, E\left(e_{j}^{2}\right)=\sigma_{j}^{2}, E\left(e_{j}, e_{i}\right)=0 \forall j \neq \mathrm{i}$.

Table 1 presents the characteristics of fourteen Brazilian bonds (Brady and Global) used in the numerical examples. Figure 2 depicts two term structures of interest rates estimated using the model just described: one term structure for Brady bonds, and the other term structure for Global bonds. 
TABLE 1 - BRAZILIAN BONDS USED IN THE ESTIMATION PROCESS

\begin{tabular}{lcccc}
\hline Bond & Type & Coupon (\%) & Duration (Years) & Maturity \\
\hline CBOND & Brady & 8.000 & 5.42 & 15-Apr-2014 \\
DCB & Brady & 7.440 & 5.13 & 15-Apr-2012 \\
DFA & Brady & 7.760 & 2.95 & 15-Sep-2007 \\
EI & Brady & 7.380 & 2.49 & 15-Apr-2006 \\
IDU & Brady & 7.840 & 0.13 & 01-Jan-2001 \\
NMB & Brady & 7.440 & 3.39 & 15-Apr-2009 \\
GLB01 & Global & 8.875 & 0.95 & 05-Nov-2001 \\
GLB04 & Global & 11.63 & 2.89 & 15-Apr-2004 \\
GLB08 & Global & 9.380 & 5.25 & 07-Apr-2008 \\
GLB09 & Global & 14.50 & 5.29 & 15-Oct-2009 \\
GLB20 & Global & 12.75 & 6.59 & 15-Jan-2020 \\
GLB27 & Global & 10.13 & 7.03 & 15-May-2027 \\
GLB30 & Global & 12.25 & 7.01 & 06-Mar-2030 \\
GLB40 & Global & 11.000 & 6.91 & 17-Aug-2040 \\
\hline
\end{tabular}

FIGURE 2 - A JOINT ESTIMATION OF TERM STRUCTURES OF BRADY AND GLOBAL MARKETS

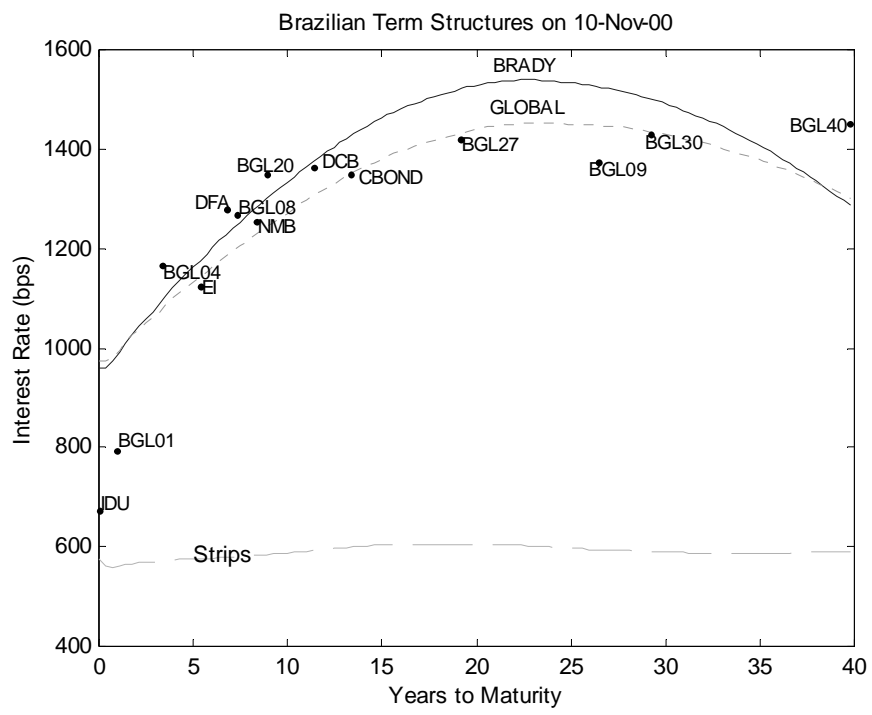

Est. econ., São Paulo, 34(2): 321-344, abr-jun 2004 


\subsection{Joint Estimation of Term Structures of Interest Rates of the Brady and Global Bonds Market}

As an example of the methodology just described, let us suppose that we are interested in estimating the Brazilian Brady and Global bonds term structures of interest rates. These two types of assets may present, during certain periods of time, substantially different levels of credit risk. Thus, estimating a unique term structure of interest rates to represent both markets may "distort" results. On the other hand, estimating separately one curve for each market may present statistical difficulties in the cases where the number of liquid assets belonging to one of these markets is small. In order to avoid these drawbacks, we apply the methodology presented in Almeida et al. (2000), which captures the difference in risk between different levels of credit risk using different credit spread functions. The result is a joint estimation procedure that estimates simultaneously the two term structures.

Consider the existence of two levels of credit risk represented by $r_{G}, r_{B}$, where the first is related to the Global bonds market, and the second to the Brady bonds market. The methodology proposes an extension to Equation (1) to capture different levels of credit risk considering the spread function depending explicitly on these levels:

$$
R\left(t, r_{G}, r_{B}\right)=B(t)+C\left(t, r_{G}, r_{B}\right), \forall t \in[0, \lambda]
$$

The spread function is still modeled as a linear combination of Legendre polynomials. The model is completely specified when the dependence on different levels of credit risk is defined. For instance, it is possible to capture the difference in credit risk using just the translation factor (Legendre polynomial of degree zero). A consequence from such a specification is:

a) The term structures of interest rates estimated simultaneously using the model differ only by parallel shifts.

Or, equivalently: 
b) When comparing all maturities of these term structures, the volatilities of the interest rates spreads differ only by a constant value.

For the first numerical example presented in this article we used a more general model. It allows the interest rates spreads of one term structure with respect to the other to present volatility differing not only by a constant value along the maturities. This flexibility can be achieved by allowing the term structures to possess also different curvatures. Thus, the model captures the difference in credit risk using the Legendre polynomials of degree zero and two (which are responsible, respectively, for parallel shifts and changes in curvature of the term structure of interest rates).

The equations for the term structures of interest rates for the Global and Brady markets are respectively (letting $\tilde{t}=\frac{2 t}{\lambda}-1, \forall t \in[0, \lambda]$ ):

$$
\begin{gathered}
R^{G}(t)=B(t)+\sum_{n \geq 0} c_{n}^{G} P_{n}(\tilde{t}) . \\
R^{B}(t)=B(t)+\left(c_{0}^{G}+c_{0}^{B}\right) P_{0}(\tilde{t})+c_{1}^{G} P_{1}(\tilde{t})+\left(c_{2}^{G}+c_{2}^{B}\right) P_{2}(\tilde{t})+\sum_{n \geq 3} c_{n}^{G} P_{n}(\tilde{t}) .
\end{gathered}
$$

The coefficients $c_{0}^{B}$ and $c_{2}^{B}$ allow the Brady term structure to present a distinct decomposition when compared to the Global term structure, with respect to parallel shifts and changes in curvature. In this particular case, the two curves present the same rotation factor with respect to the benchmark curve. Later in this article we shall investigate the use of different rotation factors.

Figure 2 depicts the Brazilian Brady and Global bonds term structures of interest rates estimated on November 10, 2000, based on the model just described, with the U.S strips playing the role of the benchmark curve. Values for the first three orthogonal factors for each curve, with their p-values, are given in Table 2 . 
TABLE 2 - ORTHOGONAL FACTORS FOR TWO BRAZILIAN TERM STRUCTURES

\begin{tabular}{lcc}
\hline Factor $^{*}$ & Value (bps) & P-Value \\
\hline Brady Translation & 747 & $0.000^{* * *}$ \\
Global Translation & 697 & $0.000^{* * *}$ \\
Rotation & 147 & $0.000^{* * *}$ \\
Brady Torsion & -239 & $0.014^{* *}$ \\
Global Torsion & -174 & $0.000^{* * *}$ \\
\hline
\end{tabular}

*The first three Legendre polynomials correspond respectively to the translation, rotation and torsion factors.

${ }^{* *}$ Statistically significant at a $5 \%$ confidence level.

${ }^{* *}$ Statistically significant at a $1 \%$ confidence level.

\section{ESTIMATING THE VALUE AT RISK OF TWO BRAZILIAN FIXED INCOME PORTFOLIOS}

Suppose we wanted to estimate the Value at Risk of two portfolios on November 10, 2000, using the model just described.

Portfolio 1 presents the following composition (see also Table 1):

a) Long US\$ 20 million in CBOND.

b) Long US\$ 20 million in DCB.

c) Long US\$ 10 million in GLB30.

d) Short US\$ 20 million in EI.

e) Short US\$ 15 million in IDU.

f) Short US\$ 15 million in GLB01.

Portfolio 2 is composed by the same bonds and the same amounts as Portfolio 1, but it presents only long positions: 
a) Long US\$ 20 million in CBOND.

b) Long US\$ 20 million in DCB.

c) Long US\$ 10 million in GLB30.

d) Long US\$ 20 million in EI.

e) Long US\$ 15 million in IDU.

f) Long US\$ 15 million in GLB01.

As mentioned before, we need first to estimate the probability distribution of the variations of the term structures. We apply the Historical Simulation approach (JORION, 2001) for estimating the interest risk in these two portfolios.

Obtaining the historical joint probability densities of the variations of the U.S strips term structure, and of all orthogonal factors in Table 2, is a computer intensive step. It requires running an optimization procedure for each day in the database to estimate the values of the orthogonal factors and, then, to estimate the historical term structures for Brady Bonds and Global Bonds. After obtaining the distributions for the orthogonal factors and for the U.S Strips, we can obtain the Brady and Global bonds term structures scenarios required by the Historical Simulation approach. In the numerical examples two hundred and fifty historical scenarios were generated. For each scenario, the associated term structures were used to price all bonds in the portfolios. At the end, we obtained the historical probability density of bond prices.

Let $\left\{\theta_{i}\right\}_{i=1, \ldots, m}$ denote the random variables which represent the returns of the bonds, $\left\{w_{i}^{(j)}\right\}_{i=1, \ldots, m}$ denote the amounts (in US\$) of each bond in the $j^{\text {th }}$ proposed portfolio, and $V_{j}$ denotes the random variable which measures the profits and losses (in US\$) of the $j^{\text {th }}$ portfolio, for $j=1,2$. We constructed the probability density of the profits and losses of the $j^{\text {th }}$ portfolio by multiplying the returns of the bonds listed in this portfolio by the amounts held on them: 


$$
V_{j}=\sum_{i=1}^{m} w_{i}^{(j)} \theta_{i}
$$

Finally, based on the probability densities of the random variables $\left\{\theta_{i}\right\}_{i=1, \ldots, m}$ and $\left\{V_{j}\right\}_{j=1,2}$ (obtained by historical simulation) we estimate the VaR of both the proposed portfolios and of each bond used in the estimation process.

For instance, Figure 3 depicts the marginal probability densities of the returns of the translation, rotation and torsion orthogonal factors related to the Brady and Global term structures of interest rates. Note from Table 3 that the five historical distributions in Figure 3 violate the hypothesis of normality. They all present kurtosis greater than three, as well as non-zero skewness.

TABLE 3 - JARQUE BERA NORMALITY TEST FOR THE FACTORS RETURNS

\begin{tabular}{lccc}
\hline Probability Density of & Skewness & Kurtosis & p-value \\
\hline Global Translation & 0.11 & 3.95 & $0.006^{*}$ \\
Global Torsion & -0.21 & 5.43 & $0.000^{\star}$ \\
Brady Translation & 0.25 & 3.79 & $0.004^{*}$ \\
Brady Torsion & -0.23 & 5.61 & $0.000^{*}$ \\
Rotation & 0.14 & 4.85 & $0.000^{\star}$ \\
\hline
\end{tabular}

${ }^{*}$ Reject the hypothesis of normality at a $1 \%$ significance level. 


\section{FIGURE 3 - MARGINAL PROBABILITY DENSITY FUNCTIONS OF THE ORTHOGONAL FACTORS}
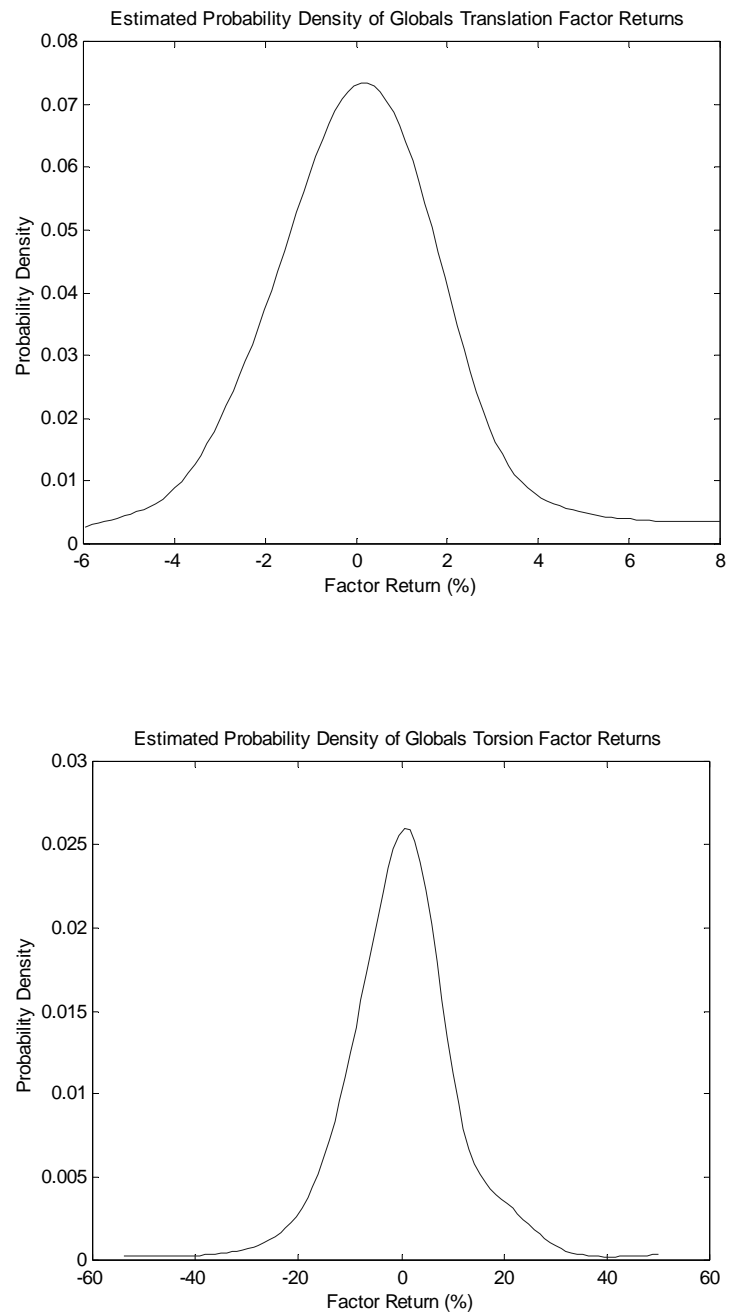

Est. econ., São Paulo, 34(2): 321-344, abr-jun 2004 

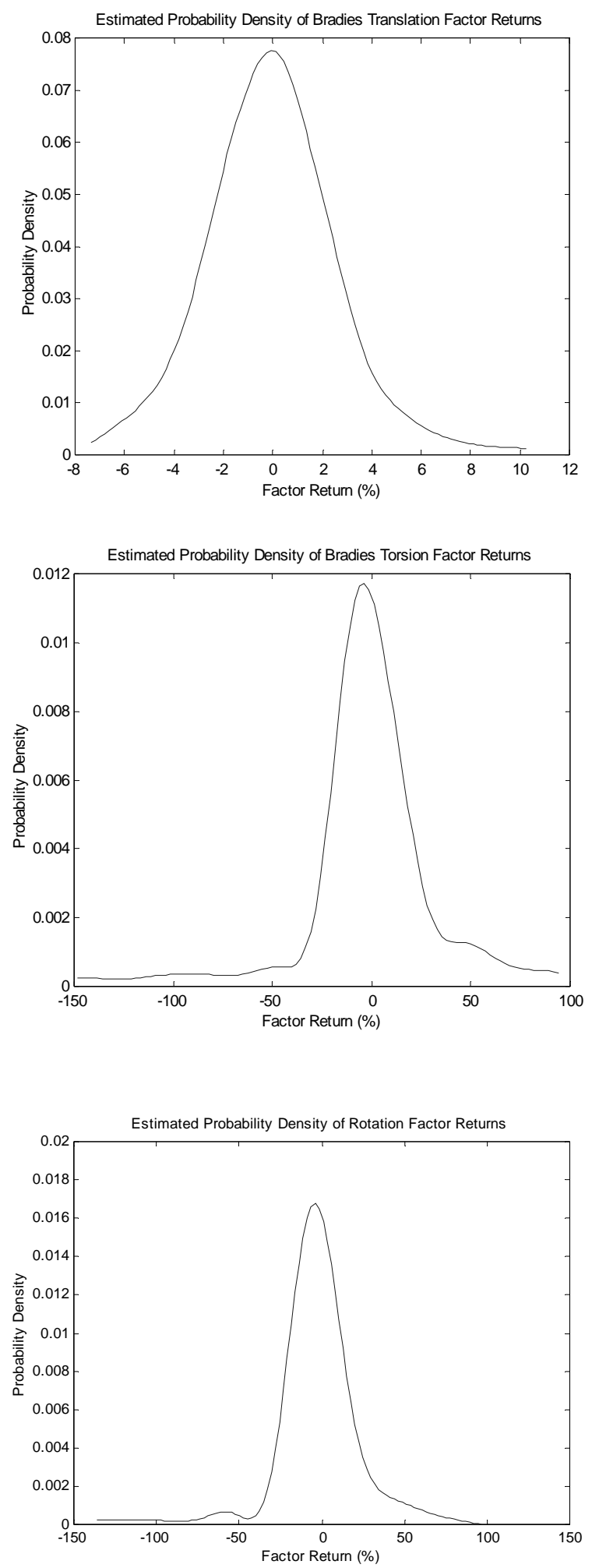

Est. econ., São Paulo, 34(2): 321-344, abr-jun 2004 
Figure 4 and Figure 5 present, respectively, the probability densities of the returns of Portfolio 1 and Portfolio 2. Note that both are skewed to the left and present fat left-tail, meaning that there is a greater probability of loosing extreme values than earning extreme values. For the reasons detailed in Duarte (1997), the Analytical Approach (JORION, 2001) is not recommended to compute the VaR of these two portfolios.

\section{FIGURE 4 - ESTIMATED PROBABILITY DENSITY FUNCTION OF} THE RETURNS OF PORTFOLIO 1

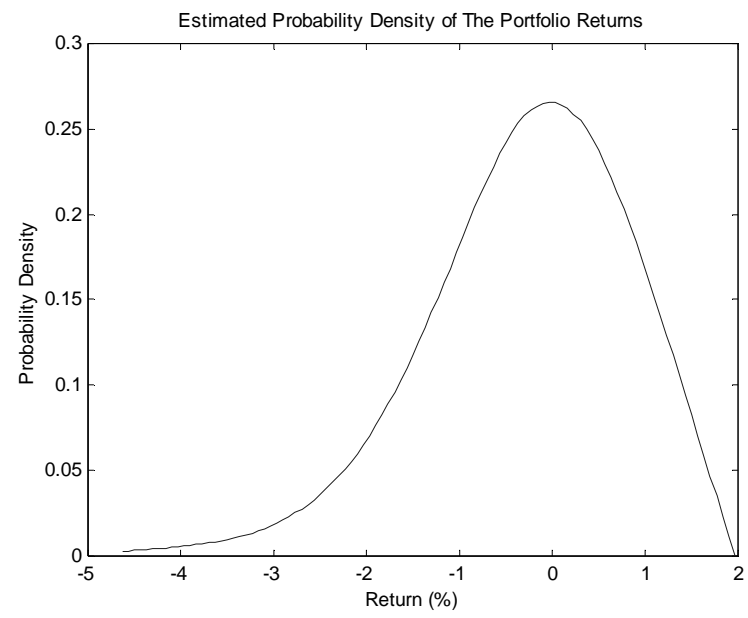

FIGURE 5 - ESTIMATED PROBABILITY DENSITY FUNCTION OF THE RETURNS OF PORTFOLIO 2

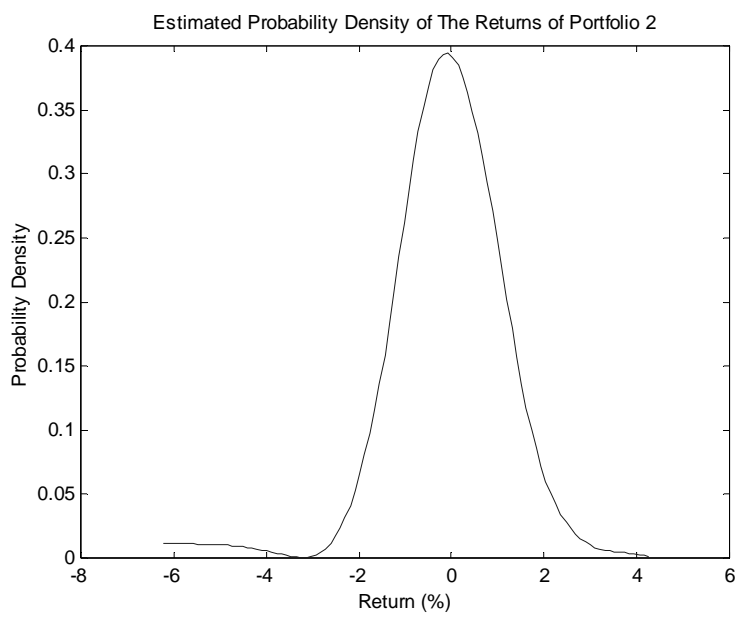

Est. econ., São Paulo, 34(2): 321-344, abr-jun 2004 
Table 4 presents the Value at Risk for each bond used in the estimation process, for two distinct confidence levels: $99 \%$ and $95 \%$. Similarly, Table 5 presents the Value at Risk for the proposed portfolios for $99 \%$ and $95 \%$ confidence levels. Table 6 shows the price correlation matrix for the bonds used in the estimation process.

TABLE 4 - ESTIMATED VALUE AT RISK FOR GLOBAL AND BRADY BONDS

\begin{tabular}{lcc}
\hline Bond & Value at Risk (99\%) & Value at Risk (95\%) \\
\hline CBOND & $-6.05 \%$ & $-3.02 \%$ \\
DCB & $-6.16 \%$ & $-3.17 \%$ \\
DFA & $-5.78 \%$ & $-3.47 \%$ \\
EI & $-5.76 \%$ & $-3.27 \%$ \\
IDU & $-0.63 \%$ & $-0.23 \%$ \\
NMB & $-6.18 \%$ & $-3.43 \%$ \\
GLB01 & $-2.91 \%$ & $-0.60 \%$ \\
GLB04 & $-7.40 \%$ & $-1.38 \%$ \\
GLB08 & $-8.21 \%$ & $-2.24 \%$ \\
GLB09 & $-7.12 \%$ & $-2.16 \%$ \\
GLB20 & $-6.50 \%$ & $-2.29 \%$ \\
GLB27 & $-5.83 \%$ & $-2.08 \%$ \\
GLB30 & $-5.92 \%$ & $-2.14 \%$ \\
GLB40 & $-4.72 \%$ & $-2.13 \%$ \\
\hline
\end{tabular}

TABLE 5 - PORTFOLIOS ESTIMATED VALUE AT RISK BASED ON HISTORICAL SIMULATION

\begin{tabular}{lcc}
\hline Portfolio & Value at Risk $(99 \%)$ & Value at Risk (95\%) \\
\hline 1 & US $\$-1,880,000$ & US $\$-770,000$ \\
2 & US $\$-3,680,000$ & US $\$-1,850,000$ \\
\hline
\end{tabular}




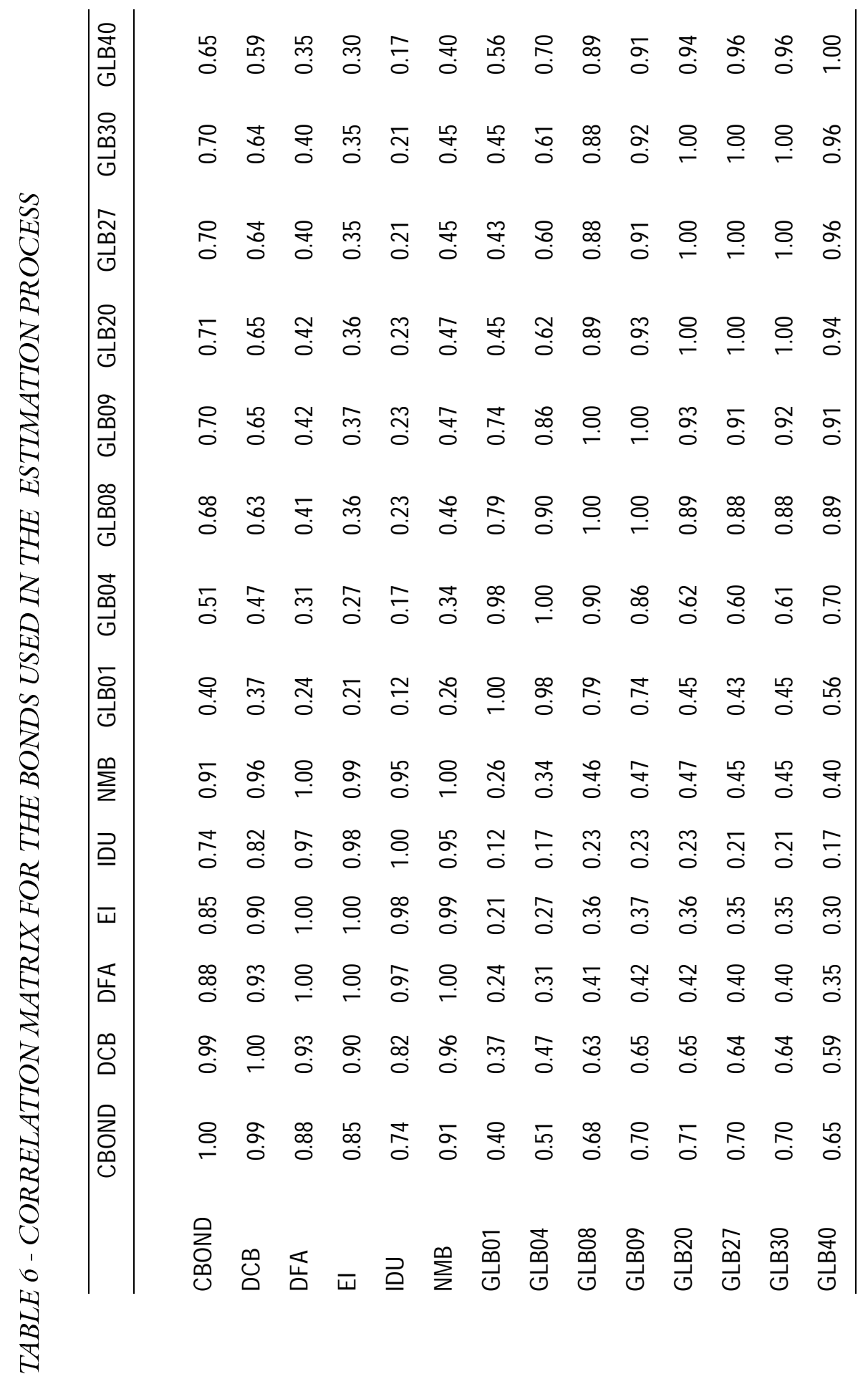

Est. econ., São Paulo, 34(2): 321-344, abr-jun 2004 
For the sake of illustration, we present two other models to decompose the spread of the Brady over the Global term structure. Table 7 presents the combinations of factors for each analyzed model. Model 1 corresponds to the model where the difference in risk is captured using only the translation factor. Model 2 captures the difference in credit risk using the translation and rotation factors. Finally, Model 3 represents the model used so far in this article (which is included here only for comparative purposes).

We provide in Figure 6 and Figure 7 the historical evolution of Brazilian Brady and Global term structures during one year of analysis, for Model 1 and Model 2, respectively.

TABLE 7 - ESTIMATING VAR USING DIFFERENT COMBINATIONS OF FACTORS

\begin{tabular}{lccc}
\hline Model & Translation & Rotation & Torsion \\
\hline 1 & $\mathrm{X}$ & & \\
2 & $\mathrm{X}$ & $\mathrm{X}$ & \\
3 & $\mathrm{X}$ & & $\mathrm{X}$ \\
\hline
\end{tabular}

\section{FIGURE 6 - HISTORICAL BRAZILIAN TERM STRUCTURES FOR MODEL 1}

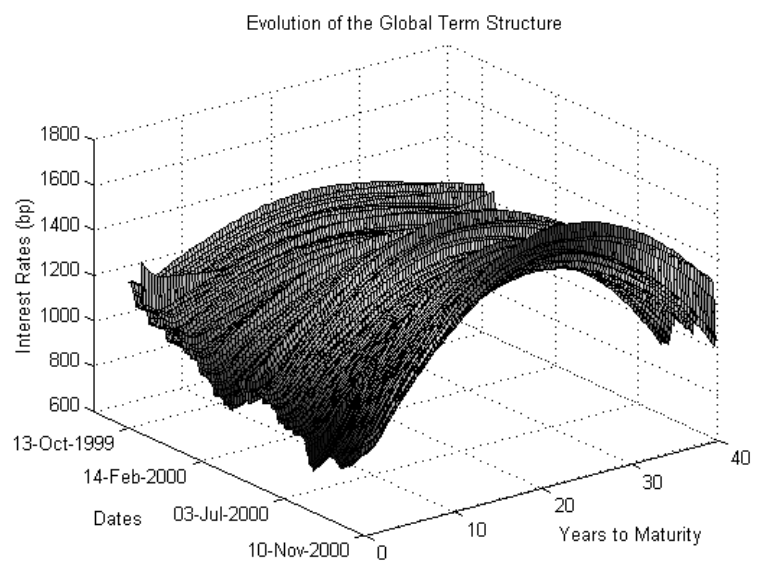




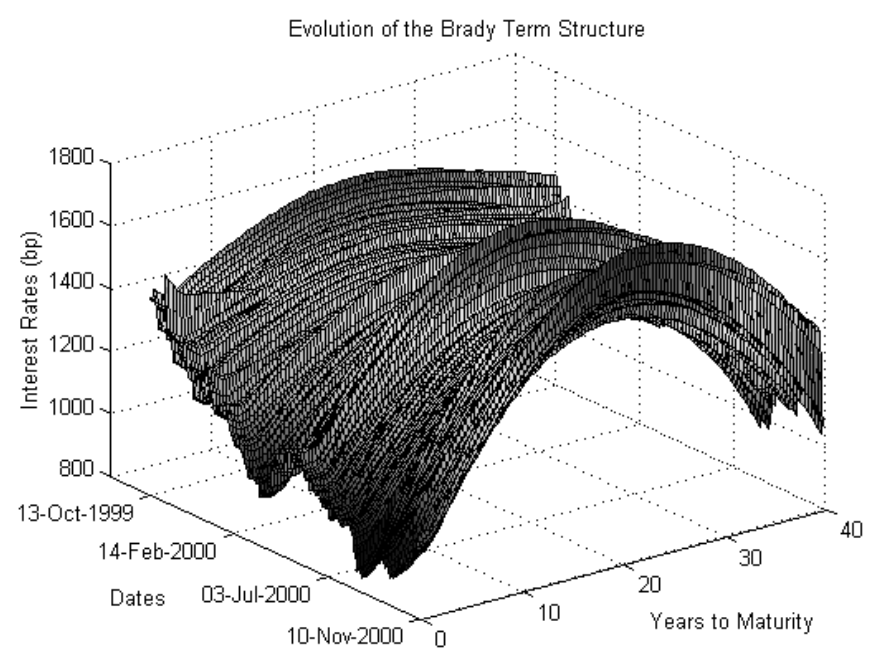

\section{FIGURE 7 - HISTORICAL BRAZILIAN TERM STRUCTURES FOR MODEL 2}

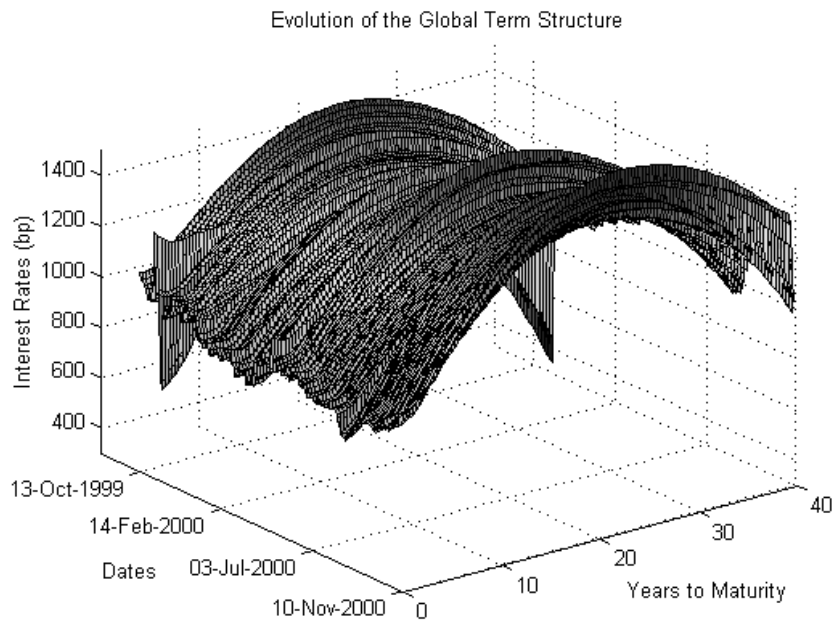

Est. econ., São Paulo, 34(2): 321-344, abr-jun 2004 


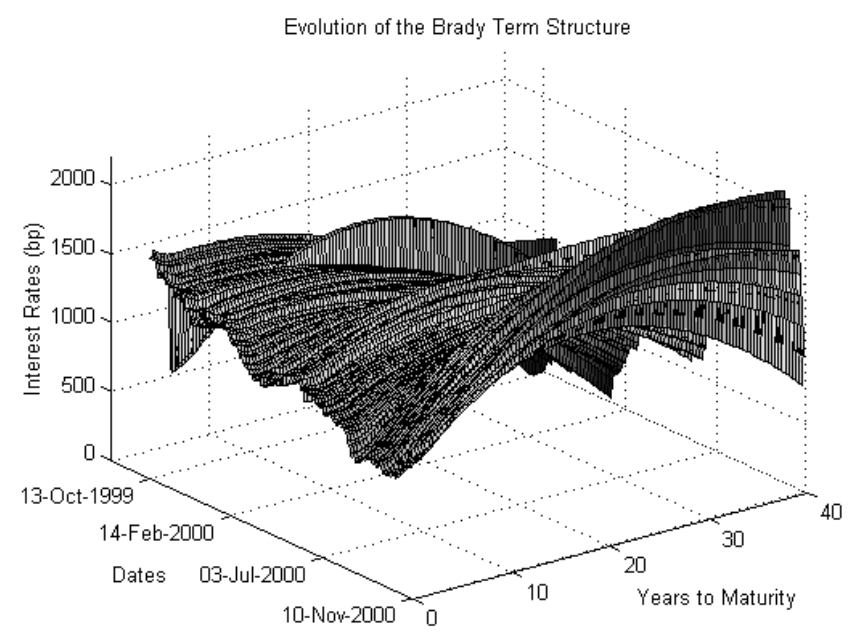

Observing these graphs, we are capable of capturing which are the most important factors responsible for interest rate risk. For instance, Figure 6 and Figure 7 reveals that the Brady rotation factor is more volatile in Model 2 than in the others. This fact is in accordance with the specification of the model, which uses an extra free variable related to the rotation factor to describe the spread of the Brady over the Global term structure. Observing now the Global term structures, Figure 6 reveals that the rotation and torsion factors become more important as risk factors for more recent observations of the time series for Model 1. On the other hand, Figure 7 indicates that the Global term structure suffers significant changes in its curvature since the beginning of the time series for Model 2. These pictures represent an interesting tool for identification of the regions where the scenarios for the evolution of the term structures might produce the most extreme movements.

Table 8 presents the estimated VaR for Portfolios 1 and 2 for the three models. It generalizes what was observed in Table 5 for Model 3: Portfolio 2 presents higher risk than Portfolio 1, for all models, for both the $99 \%$ and 95\% confidence levels.

Another interesting fact is related to the distribution of mass in the left tails of the density functions of the returns of Portfolios 1 and 2. Note that if a 
model generates the higher risk, among all models, for a fixed confidence level, it does not mean that this model generates the highest risk for another fixed confidence level. Observe also that the difference in estimated risk existent comparing the models can be very large. For instance, if we compare the VaR for Portfolio 2, at a $99 \%$ confidence level, estimated by Models 1 and 3 , we identify a difference of $30 \%$ (US\$ $-5,230,000$ and US\$ $3,680,000)$.

These remarks indicate the importance of observing the risk for different confidence levels, and also using models presenting different sources of risk to better capture the magnitude of possible losses, avoiding mathematical modeling risk when measuring market risk. The effective control of mathematical modeling risk can be quite a difficult task, as illustrated in Duarte (1997) when estimating the VaR of portfolios in the Brazilian options markets. We must say that managing mathematical modeling risk requires not only technical skills from the user, but also experience with the market risk management of fixed income portfolios of sovereign bonds issued in emerging markets.

TABLE 8 - ESTIMATED VALUE AT RISK BASED ON HISTORICAL SIMULATION

PORTFOLIO 1

\begin{tabular}{ccc}
\hline Model & Value at Risk $(99 \%)$ & Value at Risk $(95 \%)$ \\
\hline 1 & US\$ $-1,800,000$ & US $\$-880,000$ \\
2 & US\$ $-2,680,000$ & US $\$-1,870,000$ \\
3 & US\$ $-1,880,000$ & US $\$-770,000$ \\
\hline
\end{tabular}

PORTFOLIO 2

\begin{tabular}{ccc}
\hline Model & Value at Risk $(99 \%)$ & Value at Risk $(95 \%)$ \\
\hline 1 & US\$ $-5,230,000$ & US\$ $-1,760,000$ \\
2 & US\$ $-4,960,000$ & US\$ $-2,600,000$ \\
3 & US\$ $-3,680,000$ & US\$ $-1,850,000$ \\
\hline
\end{tabular}




\section{CONCLUSION}

We propose a methodology for estimating the Value at Risk of portfolios in fixed income emerging markets. It exploits the dynamics of the orthogonal factors, obtained by the decomposition of the credit spread function into a linear combination of Legendre polynomials.

This methodology produces a probability density function for the term structures of interest rates. It is possible to show that the use of the model described in Section 1.3 (to estimate the historical evolution of the whole term structures of emerging markets) generates a dynamic equivalent to the one obtained by using Principal Component Analysis in a market presenting an observable term structure. In other words, the methodology proposes the application of Principal Component Analysis in markets presenting nonobservable term structures, which is the case of fixed income emerging markets. This fact allows us to use this methodology for, at least, all fixed income applications that may apply Principal Component Analysis, which is the case of risk analysis, portfolio allocation, immunization techniques etc.

Although the portfolios presented in the numerical examples were composed by only Brazilian fixed income instruments, the methodology can be easily extended to other financial markets (such as the U.S. corporate bond market).

\section{REFERENCES}

ALMEIDA, C. I. R.; DUARTE JÚNIOR; A. M.; FERNANDES; C. A. C. Decomposing and simulating the movements of term structures of interest rates in emerging eurobonds markets. Journal of Fixed Income, 8, p. 21-31, 1998.

. Credit spread arbitrage in emerging eurobond markets. Journal of Fixed Income, 10, p. 100-111, 2000.

BARBER, J. R.; COPPER, M. L. Immunization using principal component analysis. Journal of Portfolio Management, 22, p. 99-105, 1996.

DUARTE JÚNIOR, A. M. Model risk and risk management. Derivatives Quarterly, p. 60-72, 1997. 
FABOZZI, F. J.; FRANCO, A. Handbook of emerging fixed income \& currency markets. New Hope: FJF Associates, 1997.

JORION, P. Value at risk: the new benchmark for managing financial risk. New York: McGraw-Hill, 2001.

LEBEDEV, N. N. Special functions and their applications. New York: Dover Publications, 1972.

LITTERMAN, R.; SCHEINKMAN, J. A. Common factors affecting bond returns. Journal of Fixed Income, 1, p. 54-61, 1991.

MARDIA,K. V.; KENT, J. T.; BIBBY, J. M. Multivariate analysis. New York: Academic Press, 1992.

SINGH, M. K. Value-at-risk using principal components analysis. Journal of Portfolio Management, 24, p. 101-112, 1997.

VASICEK, O. A.; FONG, H. G. Term structure modeling using exponential splines. Journal of Finance, 37, p. 339-348, 1982.

E-mail: cibsen@ibmecri.br.

Enviar toda correspondência para: Ibmec Business School; Rua Rio Branco, 108 / 5 andar; 20040-001, Rio de Janeiro, RJ, Brasil. Email: aduarte@ibmecrj.br.

E-mail: cris@ele.puc-rio.br

(Recebido em fevereiro de 2003. Aceito para publicação em janeiro de 2004). 